\title{
COVERT NETWORKS AND ANTITRUST POLICY
}

\author{
Flavia Roldán ${ }^{1}$
}

${ }^{1}$ Public-Private Sector Research Center, IESE 
The Public-Private Sector Research Center is a Research Center based at IESE Business School. Its mission is to develop research that analyses the relationships between the private and public sectors primarily in the following areas: regulation and competition, innovation, regional economy and industrial politics and health economics.

Research results are disseminated through publications, conferences and colloquia. These activities are aimed to foster cooperation between the private sector and public administrations, as well as the exchange of ideas and initiatives.

The sponsors of the SP-SP Center are the following:

- Accenture

- Ajuntament de Barcelona

- Departament d' Economia i Coneixement de la Generalitat de Catalunya

- Departament d' Empresa i Ocupació de la Generalitat de Catalunya

- Diputació de Barcelona

- Endesa

- Fundació AGBAR

- Institut Català de les Indústries Culturals

- Mediapro

- Sanofi Aventis

- ATM, FGC y TMB

The contents of this publication reflect the conclusions and findings of the individual authors, and not the opinions of the Center's sponsors. 


\title{
Covert Networks and Antitrust Policy
}

\author{
Flavia Roldán \\ Public-Private Sector Research Center, IESE Business School *
}

July, 2011

\begin{abstract}
This article studies the effectiveness of two different antitrust policies by characterizing the network structure of market-sharing agreements that arises under those settings. Market-sharing agreements prevent firms from entering each other's market. The set of these agreements defines a collusive network, which is pursued by antitrust authorities. This article shows that under a constant probability of inspection and a penalty equal to firm's limited liability, firms form collusive alliances where all of them are interconnected. In contrast, when the antitrust policy reacts to prices in both, probability of inspection and penalty, firms form collusive cartels where they are not necessarily fully interconnected. This implies that more competitive structures can be sustained in the second case than in the first case. Notwithstanding, antitrust laws may have a pro-competitive effect in both scenarios, as they give firms in large alliances more incentives to cut their agreements at once.
\end{abstract}

JEL Classification Numbers: D43, K21, L41

Keywords: market-sharing, economic networks, antitrust authority, oligopoly.

*Address for Correspondence: Flavia Roldán: Public-Private Sector Research Center, IESE Business School, Av. Pearson 21, (08034), Barcelona, Spain, E-mail: froldan@iese.edu 


\section{Introduction}

Cartels exists and they are present among us even if we are not able to see them. Collusive practices create concern to antitrust authorities, which devote considerable time and efforts in order to discover and prosecute them.

Among different collusive practices, we find market-sharing agreements. These agreements are agreements by which firms divide up a market and agree not to enter each other's territory. In the present article, market-sharing agreement are modeled as bilateral agreements and the set of these reciprocal agreements gives rise to a collusive network among firms.

One goal of antitrust authorities is to weaken firms' incentive to form and to maintain collusive agreements over time in order to increase market efficiency. This article addresses this point by studying the effectiveness of antitrust policy to deter the formation of collusive agreements in a social network context.

Toward that ends, this article examines the collusive network structure that arises under the presence of two different antitrust policies. One of these policies is defined by a fixed probability of inspection, and a penalty equal to the firm's limited liability. The other policy is characterized by a probability of inspection that depends on prices, and by a fine related to damage that collusive agreements have caused to consumers.

In the present network framework, the probability of being detected depends on the network structure as it depends on the number of agreements that each firm has signed. That is, the probability of firm $i$ 's being detected depends not only on whether firm $i$ is inspected by the antitrust authority but also on whether any firm that has formed an agreement with $i$ is inspected. If a firm is inspected and a market-sharing agreement exists, all firms involved are penalized. However, the firm in consideration may be detected without being inspected because any firm that has an agreement with it, is inspected.

When the antitrust authority reacts to prices, the previous relationship is strengthened because the probability of inspection is not fixed but depends on the agreements that each firm has signed. In this case the probability that a firm being caught depends not only on the agreements that this firm has signed but also on the number of agreements that its criminal partners have signed.

We provide the stable network characterization in the two antitrust settings. First of all, it worth saying that in the absence of the antitrust authority, a network is stable if its collusive cartels are large enough. I show that when an antitrust authority is 
considered, however, structures that are more competitive can be sustained through bilateral agreements.

Furthermore, I show that under certain conditions, the two policies have a procompetitve impact. As the probability of inspection increases, firms in large cartels have more incentives to renege on all their collusive agreements at once, and it might lead to break-down collusion.

Comparing both policies, when the probability of inspection is fixed, member's cartels are fully interconnected, i.e., components are complete. However, when the probability of inspection is sensitive to prices, components are not necessary complete. This result implies that more competitive structures may arise with respect to the first case.

This article brings together elements from the literature of social networks, collusion (particularly, market-sharing agreements), and law enforcement.

Networks is currently a very active field of research. Prominent contributions to this literature include, among others, Jackson and Wolinsky (1996), Goyal (1993), Dutta and Mutuswami (1997) and Jackson and van den Nouweland (2005). In particular, in first paper, the formation and stability of social networks are modeled when agents choose to maintain or destroy links using the notion of pair-wise stability. We follow Jackson and Wolinsky (1996) and Jackson and van den Nouweland (2004) to characterize the stable and the strongly stable networks.

Asides from these theoretical articles, there is also more and more literature that applies the theory of economic networks to models of oligopoly. In particular, the present article is closely related to Belleflamme and Bloch (2004) and Roldán (2010). Belleflamme and Bloch (2004) have analyzed the collusive network of market-sharing agreements among firms, but they do not consider the existence of antitrust authorities. Therefore, their results may be limited under those circumstances. Roldán (2010), however, studies how the presence of an antitrust authority affects the market-sharing agreements made by firms and examines the network structure that arises when each firm takes into account the cost, imposed by competition authorities, from signing these collusive agreements. She shows that under the presence of an antitrust authority more competitive structures are possible to sustain over time. The present article compares the effect of different antitrust policies in the collusive network structure.

Regarding the collusion literature, after the seminal contribution of Stigler (1950), collusive cartels have been extensively studied. For an excellent reference of this literature, see Vives (2001). 
As the present article, there are a number of articles that study the effect of antitrust policy on cartel behavior. Block et al. (1981) is a first systematic attempt to estimate the impact of antitrust enforcement on horizontal minimum price fixing. Their model explicitly considers the effect of antitrust enforcement on the decision of firms to fix prices collusively. They show that a cartel's optimal price is an intermediate price (between the competitive price and the cartel's price in absence of antitrust authority) and that this intermediate price depends on the levels of antitrust enforcement efforts and penalties. ${ }^{1}$

However, the interest for studying the effect of the antitrust policy on the collusive behavior has recently reemerged. For example, Harrington (2004, 2005) explores how detection affects cartel pricing when detection and penalties are endogenous. Firms want to raise prices but not suspicions that they are coordinating their behavior. Harrington (2005), assumes that the probability of detection is sensitive to price changes, he shows that the steady-state price is decreasing in the damage and in the probability of detection. These results are in line with the results of the present article in the sense of the pro-competitive effect of the antitrust policy. More recently, Motchenkova et al (2010) analyze the effectiveness of antitrust policy in a repeated oligopoly model when both fines and detection probabilities are endogenous. The main difference between the present article and those articles is that this article studies the impact of the antitrust policy on the collusive behavior in a social network framework.

The outline of this article is as follows: Section 2 presents the model of market sharing agreements and provides general definitions concerning networks. Section 3 characterizes the pair-wise stable and strong stable network when the probability of inspection is fixed and the penalty is equal to firm's limited liability; while Section 4 characterizes the network structure under an antitrust authority (AA) that reacts to prices. Section 5 analyzes the impact of the AA over competition under these two different policies. Section 5 concludes. All proof are relegated to the Appendix.

\footnotetext{
${ }^{1}$ Besanko and Spulber $(1989,1990)$ with a different approach, use a game of incomplete information where the firms' common cost is private information and neither the antitrust authority nor the buyers observe the cartel formation. They find that the cartel's equilibrium price is decreasing in the fines. LaCasse (1995) and Polo (1997) follow this approach.
} 


\section{The model}

I model the interaction between an antitrust agency and firms which form pair-wise collusive agreements or collusive links. The set of these collusive links gives rise to a network. I am interested in the structure of the collusive network that emerges under the presence of an antitrust authority (AA). This analysis is carried out in two different settings which will be described bellow.

\section{Networks}

Let $N=\{1,2, \ldots n\}$ denote a finite set of risk neutral symmetric firms. For any $i, j \in N$, a pair-wise relationship between the two firms is represented by a binary variable $g_{i j} \in$ $\{0,1\}$. In our context, $g_{i j}=1$ means that firm $i$ has signed an agreement with firm $j$ and vice versa, and $g_{i j}=0$ otherwise. A network $g=\left\{\left(g_{i j}\right)_{i, j \in N}\right\}$ is a description of the pair-wise relationship between firms. Let $g+g_{i j}$ denote the network obtained by adding link $i j$ to an existing network $g$; and let us denote by $g-g_{i j}$ the network obtained by deleting link $i j$ from an existing network $g$.

Some networks that play a prominent role in our analysis are the following two: the complete network and the empty network.

The complete network, $g^{c}$, is a network in which $g_{i j}=1, \forall i, j \in N$. In contrast, the empty network, $g^{e}$, is a network in which $g_{i j}=0, \forall i, j \in N, i \neq j$.

Formally, a firm $i$ is isolated if $g_{i j}=0, \forall j \neq i$ and $\forall j \in N$.

Paths and Components A path in a network $g$ between firms $i$ and $j$ is a sequence of firms $i_{1}, i_{2}, \ldots, i_{n}$ such that $g_{i i_{1}}=g_{i_{1} i_{2}}=g_{i_{2} i_{3}}=\ldots=g_{i_{n} j}=1$. We will say that a network is connected if there exists a path between any pair $i, j \in N$.

A component $g^{\prime}$ of a network $g$ is a maximally connected subset of $g$. Note that from this definition, an isolated firm is not considered a component. A component $g^{\prime} \subset g$ is complete if $g_{i j}=1$ for all $i, j \in g^{\prime}$. For a complete component $g^{\prime}, m_{i}\left(g^{\prime}\right)+1$ denote its size, i.e., it is the number of firms belonging to $g^{\prime}$. Let $N_{i}(g)=\left\{j \in N \backslash\{i\} \mid g_{i j}=1\right\}$ be the set of firms in $N \backslash\{i\}$ with whom firm $i$ has signed a collusive agreement. Let $m_{i}(g)$ be the cardinality of the set $N_{i}(g)$. 


\section{Collusive market sharing agreements}

I focus on one particular kind of collusive agreement: the market sharing agreement. A reciprocal market-sharing agreement is an agreement whereby two firms agree not to enter each other's market. ${ }^{2}$ Throughout the paper, I assume symmetric markets. Following Belleflamme and Bloch (2004), henceforth BB, I assume that each firm is associated to one market, i.e., its home market. In spite of that, each firm has incentives to enter and compete in all foreign markets. However, firm $i$ does not enter into foreign market $j$, and vice versa, if a reciprocal market-sharing agreement exists between them, i.e., if $g_{i j}=1$.

Let $n_{i}$ be the number of active firms in market $i$. That is, $n_{i}=N-m_{i}(g)+1$. Let $\pi_{j}^{i}(\cdot)$ be the profits of firm $i$ on market $j$. I assume that individual profits are decreasing in the number of active firms in the market, i.e. $\pi_{j}^{i}\left(n_{j}-1\right)-\pi_{j}^{i}\left(n_{j}\right) \geq 0$. Moreover, I assume that individual profits are log-convex in the number of active firms in the market, i.e., $\frac{\pi_{j}^{i}\left(n_{j}-1\right)}{\pi_{j}^{i}\left(n_{j}\right)} \geq \frac{\pi_{j}^{i}\left(n_{j}\right)}{\pi_{j}^{i}\left(n_{j}+1\right)} \cdot{ }^{3}$

Firm $i$ has two sources of profits. Firm $i$ collects profits on its home market, $\pi_{i}^{i}\left(n_{i}\right)$, and on all foreign market where there does not exist an agreement, $\sum_{j, g_{i j}=0} \pi_{j}^{i}\left(n_{j}\right)$. The symmetric firm and symmetric market assumptions allow us to write $\pi_{j}^{i}(\cdot)=\pi(\cdot)$. Total profits of firm $i$, therefore, can be written as follows:

$$
\Pi^{i}=\pi\left(n_{i}\right)+\sum_{j, g_{i j}=0} \pi\left(n_{j}\right)
$$

It is assumed that firms have limited liability, i.e., $\Pi^{i} \geq 0$ is the maximum amount that the firm could pay in case a penalty were imposed by an antitrust authority.

\section{The antitrust enforcement and the collusive network}

The antitrust authority is defined as a pair $\{\phi(\cdot), F(\cdot)\}$, where $\phi(\cdot) \in[0,1)$ is the probability that a market-sharing suit is initiated, and $F(\cdot) \geq 0$ represents the monetary penalty that a firm must pay if it is convicted of market-sharing agreements. That is, the AA inspects firms with a positive probability $\phi(\cdot)$, and the technology is such that when the AA inspects, if there exists a market-sharing agreement, the AA detects it.

\footnotetext{
${ }^{2}$ It is assumed that these agreements are enforceable.

${ }^{3}$ If profit functions satisfy long-convex property, then individual profits are convex in the number of active firms in the market, i.e. $\pi_{j}^{i}\left(n_{j}-1\right)-\pi_{j}^{i}\left(n_{j}\right) \geq \pi_{j}^{i}\left(n_{j}\right)-\pi_{j}^{i}\left(n_{j}+1\right)$.
} 
Moreover, the AA also identifies the two firms involved in the agreement. If a firm is sued for making a market-sharing agreement, the AA is able to detect, without error, whether a market-sharing agreement has occurred. Moreover, if it has occurred, the AA can detect the firms that signed that agreement. In such a case, both firms are penalized and each one must pay $F(\cdot)$. In this paper, I consider two regimes of antitrust policy. In one of them, the probability of inspection is constant and the pecuniary punishment is high as it is possible, that is, it is equal to the total profit of firms. In the second case, the probability of inspection depends on the number of agreement that each firm has signed and the fine is related to the damage.

In what follows I will show how the organization of collusive conspiracy interacts with the enforcement policy. Particularly, we will restrict our attention on the interaction between the structure of illegal agreements and the probability of being detected.

Given the technology of inspection assumed in this article, when a firm $i$ forms a new market-sharing agreement, it will increase its probability of being detected. That is, the probability of firm $i$ being caught by the AA depends not only on whether firm $i$ is inspected but also depends on whether any firm with which firm $i$ has a link is also inspected. ${ }^{4}$ Thus, a firm $i$ will not be detected if $i$ is not inspected and if it is not inspected any firm $j$ that has an agreement with $i$. That is, $\operatorname{Pr}($ Detected $i)=1-$ $\operatorname{Pr}($ No Detected $i)$, and $\operatorname{Pr}($ No Detected $i)=\operatorname{Pr}\left(\right.$ No inspected $i \bigcap_{\substack{j \neq i \\ g_{i j}=1}}$ No inspected $\left.j\right)$ or equivalently, ${ }^{5}$

$$
\operatorname{Pr}(\text { No Detected } i)=(1-\phi(\cdot)) \prod_{\substack{j \neq i \\ g_{i j}=1}}(1-\phi(\cdot))
$$

Therefore, the probability of being detected depends on how many agreements firm $i$ has signed, i.e., $m_{i}=N-n_{i}{ }^{6}$

From the AA's point of view, the structure of relationships described by $m_{i}=N-n_{i}$ generates scale economies on detection as

$$
\operatorname{Pr}(\text { Detected } i)=1-(1-\phi(\cdot)) \prod_{\substack{j \neq i \\ g_{i j}=1}}(1-\phi(\cdot))>\operatorname{Pr}(\operatorname{Inspected} i)=\phi(\cdot)
$$

\footnotetext{
${ }^{4}$ We only consider the immediate link.

${ }^{5}$ It is assumed that events "No inspected $i$ " and "No inspected $j$ " are independent each other.

${ }^{6}$ Let us observe that the number of terms in the operator $\prod$ is $m_{i}=N-n_{i}$.
} 
Lets now to sum up the relationship between firms and the competition authority. First, the antitrust agency commits itself by announcing the rules under which a case may become investigating and the fine to be paid if a firm is found guilty of collusion. Then, given the antitrust rules, firms have the choice of forming market sharing agreements or not. If a firm chooses the former, it gets

$$
\Pi^{i} \operatorname{Pr}(\text { Not Detected } i)+\left[\Pi^{i}-F(\cdot)\right] \operatorname{Pr}(\text { Detected } i)
$$

In the absence of any collusive agreement signed by firm $i$, its profits can be written as $\Pi^{i}=\pi(N)+\sum_{j, g_{i j}=0}^{N} \pi\left(n_{j}\right)$.

\section{Stability}

Pair-wise stable networks The following approach is taken by Jackson and Wolinsky (1996). A network $g$ is pair-wise stable if and only if: (i) $\forall i, j \in N$ such that $g_{i j}=1, \Pi^{i}(g) \geq \Pi^{i}\left(g-g_{i j}\right)$ and $\Pi^{j}(g) \geq \Pi^{j}\left(g-g_{i j}\right)$; and (ii) $\forall i, j \in N$ such that $g_{i j}=0$, if $\Pi^{i}\left(g+g_{i j}\right)>\Pi^{i}(g)$ then $\Pi^{j}\left(g+g_{i j}\right)<\Pi^{j}(g)$.

This stability notion is a relatively weak criterion in the sense that it provides broad predictions since the firm's deviations are constrained. A pair-wise stability criterion only considers deviations on a single link at a time. ${ }^{7}$ Furthermore, the pair-wise stability notion considers only deviations by a pair of players at a time. ${ }^{8}$

Nevertheless, that criterion provides a test to eliminate the unstable networks and it should be seen as a necessary, but not sufficient condition for a network to be stable.

Strongly pair-wise stable networks In order to obtain a stronger stability concept we allow deviations by coalitions of firms. We allow firms to delete some or all market-sharing agreements that they have already formed.

We say that a network is pair-wise strongly stable if it is immune to deviations by coalitions of two firms. I consider the simultaneous linking game introduced by Myerson (1991). Each firm $i$ chooses the set $s_{i}$ of firms with which it wants to form a link. Thus, $g_{i j}=1$ if and only if $j \in s_{i}$ and $i \in s_{j}$. Let $g\left(s_{1}, s_{2}, \ldots, s_{n}\right)$ denote the network formed when every $i$ chooses $s_{i}$.

\footnotetext{
${ }^{7}$ On the contrary, for example, it is possible that a firm would not benefit from forming a single link but would benefit from forming several links simultaneously.

${ }^{8}$ It could be that larger groups of player can coordinate their actions in order to all be better off.
} 
A strategy profile $\left\{s_{1}^{*}, s_{2}^{*}, \ldots, s_{n}^{*}\right\}$ is a pair-wise strong Nash equilibrium of the game if and only if it is a Nash equilibrium of the game and there does not exist a pair of firms $i$ and $j$ and strategies $s_{i}$ and $s_{j}$ such that $\Pi^{i}\left(g\left(s_{i}, s_{j}, s_{-i j}^{*}\right)\right) \geq \Pi^{i}\left(g\left(s_{i}^{*}, s_{j}^{*}, s_{-i j}^{*}\right)\right)$ and $\Pi^{j}\left(g\left(s_{i}, s_{j}, \ldots, s_{-i j}^{*}\right)\right) \geq \Pi^{j}\left(g\left(s_{i}^{*}, s_{j}^{*}, \ldots, s_{-i j}^{*}\right)\right)$ with a strict inequality for one of the two firms. A network $g$ is strongly pair-wise stable if and only if there exists a pair-wise strong Nash equilibrium of the game $\left\{s_{1}^{*}, s_{2}^{*}, \ldots, s_{n}^{*}\right\}$ such that $g=g\left(s_{1}^{*}, s_{2}^{*}, \ldots, s_{n}^{*}\right)$.

It is possible to prove that any strongly pair-wise stable network is pair-wise stable. Thus, the strong stability notion can be thought of as sufficient condition for stability.

\section{Collusive networks under a constant inspection probability and fines equals to profits}

\section{The antitrust policy}

In this part, I define an antitrust authority by a constant and exogenous probability of inspection, $\phi(\cdot)=\phi \in[0,1)$, and by a monetary penalty, $F(\cdot)=\Pi$, that a firm must pay if it is convicted of market-sharing agreements.

In the economic literature of optimal enforcement, fines are usually assumed as socially costless. Therefore, when the AT seeks to deter collusion, the fines should be set at the maximal level in order to minimize the inspection cost. ${ }^{9}$ An implication of this is that the fines need not to be related to the illegal profits or to the harm that the offenders caused. They only need to be as high as it is possible in order to deter collusion. This implication holds as long as there are not legal errors in the detection process (false convictions), or as long as the fines do not imply bankruptcy to convicted firms. Motta and Polo (2003), Rey (2003) and Spagnolo (2004) assume penalties that are independent of the damages. In contrast, Harrington (2004, 2005) and Motchenkova (2008) assume fines that are sensitive to illegal gains. In particular, Harrington (2004, 2005) considers a penalty that is sensitive to the price charged by collusive firms and also a fixed penalty with respect to the endogenous variables.

In the present case, $F(\cdot)=\Pi$, that is $F(\cdot)=\pi\left(n_{i}\right)+\sum_{k, g_{i k}=0} \pi\left(n_{k}\right)$. This case is comparable with Harrington's assumption in the sense that one part of the penalty, $\pi\left(n_{i}\right)$, is relate with the illegal gains as the number of active firms $n_{i}$ depends on the

\footnotetext{
${ }^{9}$ This holds when firms are risk-neutral.
} 
number of agreements that firm $i$ has signed. The other part of the penalty, $\sum_{k, g_{i k}=0} \pi\left(n_{k}\right)$, is fixed since it does not depends on the collusive behavior of firm $i$.

Regarding the inspection process, I assume that antitrust authorities have constant and exogenous budgets that allow them to inspect a fix number of firms, i.e. $\phi \in[0,1)$ is a constant and exogenous probability of inspection. It can be also interpreted as a surprise inspection policy, that although it may be effective, ${ }^{10}$ it is hard to find as a current practice. Consequently, when $\phi$ is constant, we rewrite the probability of detected firm $i$ as follows $\operatorname{Pr}($ Detected $i)=1-(1-\phi)^{N-n_{i}+1}$

\section{The payoffs}

By using the expression (3), it is possible to compute firm $i$ ' expected profits in this case as:

$$
(1-\phi)^{N-n_{i}+1} \Pi^{i}+\left(1-(1-\phi)^{N-n_{i}+1}\right)\left[\Pi^{i}-F(\cdot)\right]
$$

where $F(\Pi)=\Pi^{i}$ and $\Pi^{i}=\pi\left(n_{i}\right)+\pi\left(n_{j}\right)+\sum_{k \neq j, g_{k i}=0} \pi\left(n_{k}\right)$.

Then, firm $i$ 's incentive to form an agreement with firm $j$ is given by the following:

$$
\Delta \Pi_{j}^{i}=(1-\phi)^{N-n_{i}+1}\left[\pi\left(n_{i}-1\right)-\pi\left(n_{i}\right)-\pi\left(n_{j}\right)-\phi\left(\pi\left(n_{i}-1\right)+\sum_{k \neq j, g_{k i}=0} \pi\left(n_{k}\right)\right)\right]
$$

Let $J_{j}^{i}\left(n_{i}, n_{j}, n_{k} ; \phi\right)$ denote the bracket expression in (5). Then, it can be rewritten as:

$$
\Delta \Pi_{j}^{i}=(1-\phi)^{N-n_{i}+1} J_{j}^{i}\left(n_{i}, n_{j}, n_{k} ; \phi\right) \text { such that } g_{k i}=0
$$

It is worth noting that, when $\phi=0$, the firm $i$ 's incentive to form a market-sharing agreement with firm $j$ only depends on the characteristics of markets $i$ and $j$. However, when the antitrust authority exists, $\Delta \Pi_{j}^{i}$ will also depend on the characteristics of all

\footnotetext{
${ }^{10}$ Friederiszick and Maier-Rigaud (2007) argue that "suprise inspections are by far the most effective and sometimes the only means of obtanining the necessary evidence...."
} 
market $k$ in which firm $i$ is active. ${ }^{11}$

We are interested in the sign of $\Delta \Pi_{j}^{i}$ because it is what is relevant to decide whether or not one more link is formed. That is, if $\Delta \Pi_{j}^{i} \geq 0$, firm $i$ has an incentive to form an agreement with $j$. Therefore, when $\phi \neq 1, \Delta \Pi_{j}^{i} \geq 0$ only if $J_{j}^{i}\left(n_{i}, n_{j}, n_{k} ; \phi\right) \geq 0$. Hence, in the following, we will focus only on $J_{j}^{i}\left(n_{i}, n_{j}, n_{k} ; \phi\right)$.

Forming one more link has several conflicting consequences. From firm $i$ 's point of view, notice that when a link is formed with firm $j$, firm $j$ agrees not to enter market $i$. Therefore, the number of active firms in market $i$ will decrease and it increases its profits by $\pi\left(n_{i}-1\right)-\pi\left(n_{i}\right)$. Given the reciprocal nature of this agreement, firm $i$ does not enter market $j$ either. Then, firm $i$ loses access to foreign market $j$ and it decreases its profits by $-\pi\left(n_{j}\right)$. Additionally, if firm $j$ is inspected, and it is inspected with probability $\phi$, firm $i$ will lose $\pi\left(n_{i}-1\right)+\sum_{k \neq j, g_{k i}=0} \pi\left(n_{k}\right)$.

Note that, as $\pi(\cdot)$ is a decreasing function, when $n_{j}$ decreases, it decreases the incentive to lose a more profitable market by forming a link. Then, $J_{j}^{i}$ is increasing in $n_{j}$

Likewise, $J_{j}^{i}$ is increasing in $n_{k}$. As $n_{k}$ gets smaller, the expected costs of signing an agreement with $j$ become greater. ${ }^{12}$ Hence, it decreases the incentive to form a collusive agreement.

On the other hand, the relationship between $J_{j}^{i}$ and $n_{i}$ is ambiguous. As $\pi(\cdot)$ is a convex function, when the number of competitors in its home market decreases, $\pi\left(n_{i}-1\right)-\pi\left(n_{i}\right)$ increases, hence $J_{j}^{i}$ increases. However, in such a case, $\phi \pi\left(n_{i}-1\right)$ increases, i.e., the expected cost of forming an agreement increases. Hence, this reduces the incentive to form it.

Concerning the antitrust policy, when the probability of inspection $\phi$ increases, $J_{j}^{i}$ decreases, because it increases the expected cost of forming a link.

\footnotetext{
${ }^{11}$ We just consider the case when $m_{i}=N-n_{i} \neq 0$. However, when firm $i$ is isolated, i.e. $m_{i}=$ $N-n_{i}=0$, the firm $i$ 's incentive to form an agreement is slightly different from (5). That is, $\Delta \Pi=\pi(N-1)(1-\alpha)^{2}-\pi(N)-\pi\left(n_{j}\right)-\sum_{k \neq j, g_{k i}=0} \pi\left(n_{k}\right)\left(1-(1-\alpha)^{2}\right)$. ${ }^{12}$ The expected cost is $-\left(\alpha \sum_{k \neq j, g_{k i}=0} \pi\left(n_{k}\right)\right)$.
} 


\section{The network characterization}

In this section, we will characterize pair-wise stable and strongly pair-wise stable networks under an AA defined by a fixed probability of inspection and a fine equal to the total profit of a guilty firm. Let us recall that the pair-wise stability notion might be thought of as a necessary but not sufficient condition for stability, and the strong pair-wise stable criterion provides a sufficient requirement for a network to be stable over time. Also, recall that any strong pair-wise stable network is pair-wise stable.

Proposition 1 A network $g$ is pair-wise stable if and only if it can be partitioned into a set of isolated firms and fully interconnected distinct components, $g_{1}, \ldots, g_{L}$ of different sizes $m\left(g_{l}\right) \neq m\left(g_{l^{\prime}}\right), \forall l, l^{\prime}$ such that neither an isolated firm has an incentive to form a link with another isolated one nor a firm $i$ that belongs to the smallest component has an incentive to cut a link with a firm inside it.

The next Section shows that in this context the pair-wise stable network always exists.

It is important to note that the AA imposes a change in the minimal size of the components and it does not restrict the set of isolated firms. In the absence of the AA, i.e., the BB's setting, a network is stable if its alliances are large enough. That is, the complete components have to reach a minimal size, i.e., $m^{*}$.

However, under the presence of the AA, that threshold, depends on $\phi$ and on $g$.

\section{Pair-wise strongly stable collusive network}

We refine the set of stable networks by using the strong stability condition. Now we allow firms to delete a subset of links already formed and we will study when a firm has no incentive to renege on its agreements. This point is very important in our context because a network composed by large alliances will be hard to sustain.

Proposition 2 A network $g$ is pair-wise strongly stable if and only if it is pair-wise stable and no firm prefers to cut all its agreements at once, that is

$$
\begin{array}{r}
(1-\phi)^{N-n+1} \pi(n) \geq \pi(N)+(N-n) \pi(n+1)+\sum_{k, g i=0} \pi\left(n_{k}\right)\left(1-(1-\phi)^{N-n+1}\right), \\
\forall n=N-m+1 \text { and } \forall m=m\left(g_{l}\right)
\end{array}
$$


Accordingly, the fact that a firm has no incentives to renege on all its links at once is a sufficient condition for strong stability. To see this, assume that a firm reneges on one of its agreements. Then, it gains access to a market whose profits are, at least, equal to the profit it makes on its home market after cutting a link. Therefore, if a firm has incentive to cut one agreement, the most profitable deviation for it is to renege on all its agreements at once.

Thus, in a strongly stable network, component sizes satisfy a more demanding condition.

It is worth remarking that a strongly stable network may fail to exist. Notwithstanding, one important advantage of the strong criterion is to provide a more accurate prediction of which network structures will prevail.

\section{The AA and the set of stable networks}

In this setting, the presence of the antitrust authority imposes a cost to each formed link, and as a result, the expected gain of being a part of a collusive agreement may not be positive. ${ }^{13}$ That is, the expected sanction imposed by the AA affects the incentive participation constraint of each potential alliance's member, and in turn changes the set of possible network structures that can arise.

Given the network characterization of the previous section, we now analyze which kind of stable networks can be sustained at different levels of the antitrust enforcement.

\section{The set of pair-wise stable networks}

First of all, a complete network is always pair-wise stable for sufficiently low $\phi$ 's. Let us define $\phi^{c}:=1-\frac{2 \pi(2)}{\pi(1)}$.

Proposition 3 The complete network $g^{c}$ is pair-wise stable if and only if $\phi \leq \phi^{c}$.

Being a part of a collusive agreement entails positive benefits. To serve a link increases the profits of firms that participate in it, i.e., $\pi\left(n_{i}\right)$ is decreasing in $n_{i}$. Therefore, the complete network will be pair-wise stable as long as its costs, i.e., the expected sanction are sufficiently low.

$$
{ }^{13} \text { It is, } J_{j}^{i}:=\pi\left(n_{i}-1\right)-\pi\left(n_{i}\right)-\pi\left(n_{j}\right)-\alpha\left(\pi\left(n_{i}-1\right)+\sum_{k \neq j, g_{k i}=0} \pi\left(n_{k}\right)\right), \forall i, j .
$$


Second, the empty network arises as pair-wise stable for sufficiently high $\phi$ 's. Let us define $\phi^{e}(N):=1-\left[\frac{N \pi(N)}{[\pi(N-1)+(N-2) \pi(N)]}\right]^{\frac{1}{2}}$, for $\forall N \in[3, \infty)$ and $\phi^{e}(N)<1$.

Proposition 4 For $\forall N \in[3, \infty)$, the empty network $g^{e}$ is pair-wise stable if and only if $\phi>\phi^{e}(N)$.

For an isolated firm, $\phi^{e}(N)$ is the threshold from which it has no incentive to participate in an agreement when all other firms also remain isolated. When $\phi>\phi^{e}(N)$, the expected costs to form a link are so high, relative to its benefits, that no two firms will sign an agreement.

Moreover, observe that $\phi^{e}(N)$ is strictly decreasing in $N$. That is, as $N$ increases, the "loot" becomes less "attractive" (i.e., $\pi(N)$ is decreasing in $N$ ), and therefore the threshold will get smaller.

By straightforward computations, we can see that $\phi^{e}(N)<\phi^{c}$. Consequently, from the above Propositions, we claim the following:

Claim 1 For $\phi \in\left(\phi^{e}(N), \phi^{c}\right], g^{e}$ and $g^{c}$ belong to the set of pair-wise stable networks.

From Proposition 3 and 4, we can state that pair-wise stable networks always exist. That is, first, for $\phi \leq \phi^{c}$, the complete network belongs to the set of stable networks. Second, for $\phi>\phi^{e}(N)$, the empty network will be stable. And given that $\phi^{e}(N)<\phi^{c}$, for $\phi \in\left(\phi^{e}(N), \phi^{c}\right], g^{e}$ and $g^{c}$ arise as pair-wise stable configurations.

When $\phi \neq 0$ there exists a positive probability of being caught in a market-sharing agreement. Consequently, there exists a positive probability of losing profits not only in the market where the agreement is signed but also in markets in which the firm is active, i.e. in markets where the firm does not collude.

For firms in smaller alliances the cost of forming a link becomes more significant, relative to their benefits. That is, a firm $i$ inside a small alliance does not have much to gain and has a lot to lose when one more link is made. More precisely, by signing an agreement, it gains $(1-\phi) \pi\left(n_{i}-1\right)-\pi\left(n_{i}\right)$, that gets smaller as the alliance is smaller; ${ }^{14}$ and it loses not only the access to profits on foreign market $j, \pi\left(n_{j}\right)$, but it also loses, in expected terms, $\phi \sum_{k: g_{i k}=0} \pi\left(n_{k}\right)$.

\footnotetext{
${ }^{14}$ Remember that the number of active firms is greater in smaller components.
} 
Therefore, firms in smaller components are more sensitive to the antitrust enforcement.

The intuition provided above is summarized in the next Proposition. However, before introducing it, let us define

$$
\phi^{*}\left(n_{i}\right):=\frac{\pi\left(n_{i}-1\right)-2 \pi\left(n_{i}\right)}{\pi\left(n_{i}-1\right)+\sum_{k \neq j, g i k=0} \pi\left(n_{k}\right)}
$$

That is, at $\phi^{*}\left(n_{i}\right)$ a firm $i$, with $n_{i}$ competitors in its home market, is indifferent to form a link or not (i.e., $\left.J_{j}^{i}=0\right)$. Therefore, when $\phi>\phi^{*}\left(n_{i}\right)$, then $J_{j}^{i}<0$, and firms $i$ and $j$ do not sign a collusive agreement.

Proposition 5 For firm $i \in g_{1}$ and firm $j \in g_{2}$ such that $m\left(g_{1}\right)<m\left(g_{2}\right)$, then $\phi^{*}\left(n_{1}\right)<\phi^{*}\left(n_{2}\right)$.

From the Proposition follows that the threshold is smaller for firms in smaller alliances (with larger number of competitors in their home markets). Then, as $\phi$ becomes greater, the AA firstly tears down small alliances, i.e., the smaller components are more sensitive to the antitrust policy. In the limit, firms must decide to form a very large alliance (complete network) or no alliance at all (empty network).

Proposition 6 For $\phi=\phi^{c}>0$, the only pair-wise stable networks are $g^{e}$ and $g^{c}$.

Then, by setting $\phi>\phi^{c}$, the AA completely deters the formation of collusive agreements.

\section{The set of pair-wise strongly stable networks}

Now, we turn our attention to strongly stable notion and we answer which kinds of networks arise as the AA changes its enforcement level. From the previous section, we know that there will be some pair-wise stable networks that will not be stable against changes in the agreements made by firms. By applying (6), we assert the following:

Proposition 7 As $\phi$ becomes greater, firms in large components have more incentives to delete all links at once. 
That is, as $\phi$ increases, the strongly stable condition is harder to sustain in larger components. In other words, faced with increasing $\phi$, a firm has to consider whether to maintain or to destroy its agreements. Therefore, the firm balances the pros and the cons of any decision. Namely, if a firm maintains its agreements, its benefits are $(1-\phi)^{N-n+1}\left[\pi(n)+\sum_{k, g i=0} \pi\left(n_{k}\right)\right]$.

Let us note that these benefits decrease as the probability of inspection $(\phi)$ increases, and the fall in the expected benefits is higher as $m=N-n$ is higher.

Instead, if the firm decides to destroy all its agreements, it is not only not penalized now by the AA, but also it will gain access to markets where it was colluding before. In such a situation, it will make profits on all these new foreign markets, i.e., $(N-n) \pi(n+1)$. Let us observe that these markets are more profitable as the number of competitors on them is smaller, i.e., as $m=N-n$ is larger.

Therefore, firms belonging to larger alliances have more incentives to cut all its agreements at once as the AA increases the cost of forming links.

Now, let us consider the empty network under the strongly stable notion.

It is worth noting that if $g^{e}$ is pair-wise stable, it is also strongly pair-wise stable, as the condition (6) is always satisfied for firms that remaining alone. That is, in an empty network, firms do not have any link, so the condition of not having incentives to renege on all agreements at once, is redundant for any $i \in g^{e}$. Hence, we claim that

Claim $2 \forall \phi>\phi_{e}(N)$ the empty network is always strongly pair-wise stable.

Accordingly, if for some $\phi>\phi_{e}(N)$ all alliances have been torn down by the antitrust policy, the only network configuration that exists is the empty one.

\section{Examples}

The following examples illustrate the changes that the AA imposes in the set of pairwise stable networks. ${ }^{15}$

Example 1 Pair-wise stable (ps) networks. Cournot competition with exponential inverse demand function $P(Q)=e^{-Q}$

\footnotetext{
${ }^{15}$ See Roldán, 2008 for all calculation details.
} 
Let us recall that in this context $\pi(n)=e^{-n}$. Assume that $N=5$. The following table depicts the set of pair-wise stable networks for different values of the antitrust policy. First of all, it is useful to clarify some notations there.

In the table, the complete network is represented by $\{5\}$ and, for example, $\{3,1,1\}$ denotes a network decomposed into two isolated firms and one complete component of size three.

\section{Table 2}

\begin{tabular}{cr}
\hline$\phi$ & Set of ps networks \\
$\phi \in[0 ; 0.015)$ & $\{3,2\},\{4,1\},\{5\}$ \\
$\phi \in[0.015 ; 0.04)$ & $\{3,1,1\},\{4,1\},\{5\}$ \\
$\phi \in[0.04 ; 0.065)$ & $\{2,1,1,1\},\{3,1,1\},\{4,1\},\{5\}$ \\
$\phi \in[0.065 ; 0.21)$ & $\{1,1,1,1,1\},\{3,1,1\},\{4,1\},\{5\}$ \\
$\phi \in[0.21 ; 0.25)$ & $\{1,1,1,1,1\},\{4,1\},\{5\}$ \\
$\phi \in[0.25 ; 0.26)$ & $\{1,1,1,1,1\},\{5\}$ \\
$\phi>0.26$ & $\{1,1,1,1,1\}$ \\
\hline
\end{tabular}

Thus, when $\phi$ is sufficiently low (i.e., $\phi<0.015)$ the presence of the AA does not change the set of pair-wise stable networks. However, when the antitrust enforcement is sufficiently high (i.e., $\phi>0.26$ ) the only pair-wise stable network is the empty one, hence all firms are active in all markets.

Consider now values for $\phi$ 's between these two extreme cases. Although different configurations arise, the main features to be highlighted are the following two. First, when $\phi$ increases, more structures that are competitive can be sustained through bilateral agreements. In particular, when $\phi$ becomes greater, the smaller components are more sensitive to the antitrust policy. For example, when $\phi \in[0.015 ; 0.04)$ the network structure $\{3,2\}$ is not stable because firms in smaller components have incentives to cut their agreements and the network $\{3,1,1\}$ becomes stable. ${ }^{16}$ Second, as $\phi$ increases the set of stable network configurations becomes more polarized. That is, in our analytical example, when $\phi \in(0.25 ; 0.26)$ the empty or complete networks are the only possible stable network configurations. This can be understood because the AA imposes costs of forming links and it reduces the profitability of each one. Hence, firms decide either to form more and more links, i.e. reduce the number of competitors in their home

\footnotetext{
${ }^{16}$ Likewise, it is noteworthy that the graph $\{3,1,1\}$ is not pairwise stable in the BB's setting, i.e., when $\alpha=0$.
} 
markets, in order to balance their benefits with their cost, or not forming a link at all and by doing that they avoid the costs levied by the AA.

Now, the next example illustrates two special features of the strong criterion and the impact of the AA on the set of strongly stable networks.

Example 2 Pair-wise strongly stable (pss) networks. Cournot competition for exponential inverse demand function: $P(Q)=e^{-Q}$

As in the last example, assume that $N=5$. Given that a pair-wise strongly stable network is always pair-wise stable, it suffices to check condition (6) for all network structures in Table 2 at different levels of the antitrust policy.

Table 3

\begin{tabular}{crr}
\hline$\phi$ & Set of ps networks & Set of pss networks \\
$\phi \in[0 ; 0.015)$ & $\{3,2\},\{4,1\},\{5\}$ & $\{3,2\}$ \\
$\phi \in[0.015 ; 0.04)$ & $\{3,1,1\},\{4,1\},\{5\}$ & it fails to exist \\
$\phi \in[0.04 ; 0.065)$ & $\{2,1,1,1\},\{3,1,1\},\{4,1\},\{5\}$ & $\{2,1,1,1\}$ \\
$\phi \in[0.065 ; 0.21)$ & $\{1,1,1,1,1\},\{3,1,1\},\{4,1\},\{5\}$ & $\{1,1,1,1,1\}$ \\
$\phi \in[0.21 ; 0.25)$ & $\{1,1,1,1,1\},\{4,1\},\{5\}$ & $\{1,1,1,1,1\}$ \\
$\phi \in[0.25 ; 0.26)$ & $\{1,1,1,1,1\},\{5\}$ & $\{1,1,1,1,1\}$ \\
$\phi>0.26$ & $\{1,1,1,1,1\}$ & $\{1,1,1,1,1\}$ \\
\hline
\end{tabular}

First of all, the example clarifies that the possible set of stable networks is reduced by using the strongly stable criterion. However, the strongly stable network might fail to exist and this is what happens for $\phi \in[0.015 ; 0.04)$.

Second, the incentive to free ride and delete all links is higher in larger alliances. That is, when a firm that belongs to a large alliance cuts all its agreements at once, it will recover access to more profitable markets than a firm belonging to a small component. In the example, the complete network $\{5\}$ and the stable network $\{4,1\}$ do not pass the strongly stable condition. By extending this argument, the empty network is the only strongly stable network for $\phi>0.065$.

Therefore, the antitrust policy is on the side of competition as long as it gives firms in large alliances more incentives to renege on their agreements at once. 


\section{Collusive networks under endogenous antitrust enforcement}

\section{The antitrust policy}

In the EU and in the US, the current laws set a ceiling to the maximum fine, and try to relate the penalty to cartel's consequences. The underlying reasons behind these two features are the concern about firms' ability to pay and the presence of legal errors.

That is, too high fines may put at risk the firms ability to continue compete in the future. This is the reason for which antitrust authorities establish a maximum on fines.

On the other hand, legal errors may deter some socially desirable behavior, like some forms of legal cooperation between firms which may be misjudged as collusive. In this case, the fine must be related to the harm caused or the gains produced to the cartel's members.

In this section, I assume that the fine is equal to the damage, $x(\cdot)$, caused by the collusive firms. It is defined as the difference between the actual firm's profits and the profits that a firm would have gotten in the absence of any collusive agreement. That is,

$$
x(n)=[\pi(n)-\pi(N)] ; \quad x^{\prime}<0, x^{\prime \prime}<0
$$

Regarding the inspection process, it is worth noting that in recent antitrust cases, investigations have begun with a complaint from buyers. That is, buyers observe anomalous prices and share their suspicions with competition authorities.

In this part, I assume that the probability of inspection, $\phi(\cdot)$, is related to the price $p(\cdot)$. Since, price level depends on the number of active firms in a market, the probability of inspection will finally depend on the number of active firms in the market. ${ }^{17}$ That is,

$$
\phi(\cdot) \equiv \phi(n) ; \quad \phi^{\prime}<0, \phi^{\prime \prime}<0
$$

Consequently, the probability of firm $i$ be detected, $\varphi(\cdot)$, is equal to:

$$
\varphi\left(n_{i}, n_{j}\right)=1-\left(1-\phi\left(n_{i}\right)\right) \prod_{j: g i j=1}\left(1-\phi\left(n_{j}\right)\right)
$$

The likelihood that $i$ be detected increases as the number of active firms in the home

\footnotetext{
${ }^{17}$ Alternatively, the probability of firm $i$ be inspected depends on the number of links that firm $i$ has formed.
} 
market of firm $i$ decreases as well as the number of active firms in home market of a collusive partner of $i^{18}$ also decreases.

\section{The payoffs}

Given the network $g$, firm $i$ 's profits are $\Pi^{i}=\pi\left(n_{i}\right)+\sum_{k, g_{i k}=0} \pi\left(n_{k}\right)$. Under the presence of an AA, they will be:

$$
\pi\left(n_{i}\right)+\sum_{k, g_{i k}=0} \pi\left(n_{k}\right)-x\left(n_{i}\right) \varphi\left(n_{i}, n_{l}\right) ; \quad \forall l \text { such that } g_{i l}=1
$$

Let us assume now that firm $i$ is considering to sign an agreement with firm $j$. Consequently, firm $i$ compares profits it obtains without the market sharing agreement with firm $j$, with firm's $i$ profits when it signs an agreement with firm $j$. Therefore, in this case, the firm's $i$ incentive to sign an agreement with firm $j\left(J_{j}^{i}\right)$ is given by the following expression:

$$
\begin{aligned}
& J_{j}^{i}=\pi\left(n_{i}-1\right)-\pi\left(n_{i}\right)-\pi\left(n_{j}\right)-\left[x\left(n_{i}-1\right) \varphi\left(n_{i}-1, n_{j}-1, n_{l}\right)-x\left(n_{i}\right) \varphi\left(n_{i}, n_{l}\right)\right] \\
& \quad \forall l \neq j \text { such that } g_{i l}=1 .
\end{aligned}
$$

In the current case, the firm $i$ 's incentives to sign an agreement with firm $j$ depends not only on the structure of market $i$ and $j$ but also on market's structure of all $i$ 's collusive partners.

Note that as $\pi(\cdot)$ is a convex function, $\pi\left(n_{i}-1\right)-\pi\left(n_{i}\right)$ increases as $n_{i}$ decreases. However, as $n_{i}$ decreases, it increases not only the fine that $i$ would have to pay but also it increases the probability with which firm $i$ is detected. Therefore, the relationship between $J_{j}^{i}$ and $n_{i}$ is ambiguous.

On the other hand, as $\pi(\cdot)$ is a decreasing function, $n_{j}$ decreases, the cost of form a collusive agreement increases. Additionally, as $n_{j}$ decreases, the probability of firm $i$ be detected increases. Then, it also increases the expected cost of sign an agreement with $j$. Therefore, the firm $i$ 's incentives to sign an agreement with firm $j$ decrease as $n_{j}$ decreases. Consequently, $J_{j}^{i}$ is an increasing function of $n_{j}$.

Finally, $J_{j}^{i}$ is also an increasing function of $n_{l}$ since $\varphi(\cdot)$ is a decreasing function on its argument. Therefore, as $n_{l}$ decreases, the expected cost of sign an agreement with

\footnotetext{
${ }^{18}$ All $j$ such that $g_{i j}=1$.
} 
firm $j$ increases, and decreases the incentives to sign an agreement between firm $i$ and $j$.

\subsection{The network characterization}

First of all, let us observe that a necessary condition for $J_{j}^{i} \geq 0$ is $\pi\left(n_{i}-1\right)-\pi\left(n_{i}\right)-$ $\pi\left(n_{j}\right)>0$ and $\pi\left(n_{j}-1\right)-\pi\left(n_{j}\right)-\pi\left(n_{i}\right)>0$. Consequently, this implies that if $g_{i j}=1$, then $n_{i}=n_{j}=n .{ }^{19}$

Therefore, I rewrite $J_{j}^{i} \geq 0$ as:

$$
J_{j}^{i}=\pi(n-1)-2 \pi(n)-[x(n-1) \varphi(n-1, n-1, n)-x(n) \varphi(n, n)]
$$

Let us define $\underline{n}^{*}$ as the minimum number of active firms in a market such that $J_{j}^{i} \geq 0$. Alternatively, let us denote $\bar{m}^{*}=N-\underline{n}^{*}$ as the maximal number of agreements such that this condition holds.

Now, let us denote by $\bar{n}^{*}$ the maximal number of active firms in a market such that $\pi(n-1)-2 \pi(n)>0$. Alternatively, let us define $\underline{m}^{*}=N-\bar{n}^{*}$ as the minimal number of agreements that a firm has such that that condition holds.

Finally, let us note that given the conditions that define each threshold, it is clear that $\underline{n}^{*}<\bar{n}^{*}$.

In this setting, when an endogenous AA exists, the characterization of a pair-wise stable network is as follow.

Proposition 8 A pair-wise stable network can be partitioned into a set of isolated firms and components each of which has the same number of links or agreements, such that:

a) When in a pair-wise stable network $\max _{l=1,2, \ldots, p}\left\{m\left(g_{l}\right)\right\}=\bar{m}^{*}+1$, this largest component is complete. Moreover, if there exist more than one component, they are also complete and their sizes could be equal to the size of the largest component. Components whose sizes are less than the size of the largest component, they have different sizes. In each component each firm has at most $\bar{m}^{*}$ agreements.

b) When in a pair-wise stable network, $\max _{l=1,2, \ldots, p}\left\{m\left(g_{l}\right)\right\}>\bar{m}^{*}+1$, this largest component is not fully interconnected. Moreover, if there exist more than one component, they might not be complete and their sizes could be equal to the size of

\footnotetext{
${ }^{19}$ See Proof Lemma 1, Roldán (2008).
} 
the largest component. Components whose sizes are greater than $\bar{m}^{*}+1$ are not complete and their members will have $\bar{m}^{*}$ agreements. On the contrary, components whose sizes are smaller or equal to $\bar{m}^{*}+1$, they are fully interconnected with different sizes and their members will have at most $\bar{m}^{*}$ agreements.

Given $\bar{m}^{*}$, when the size of a component is greater than $\bar{m}^{*}+1$, firms within that component are not fully interconnected. Accordingly, in such a case, components are not complete. Additionally, since each firm in a collusive agreement must have the same number of links as its partners, components are symmetric, i.e. all firms within a component have the same number of links.

\section{Pair-wise strongly stable collusive network}

We are interested in which kind of network are likely to survive. Consequently, we use the strong stability definition in order to refine the set of stable networks.

A network $g$ is pair-wise strongly stable if and only if it is pair-wise stable and no firm prefers to cut all its agreements at once, that is

$\pi(n)-x(n) \varphi(n, n) \geq \pi(N)+(N-n) \pi(n+1) \quad \forall n=N-m+1$ and $\forall m=m\left(g_{l}\right)$

That is, since each firm could unilaterally break the agreement it has, for a strong stable network it is necessary that the net expected benefits of maintaining agreements exceed the benefits to cut the $N-n$ agreements at once.

\subsection{The AA and the set of stable networks}

In this section, I analyze the impact that an endogenous AA has in the market structures that can arise. In particular, I address under which circumstances the complete network, i.e. $N$ local monopolies, may arise. Moreover, I analyze under which conditions for the antitrust policy it is possible to observe more competitive market structures.

Proposition 9 The complete network $g^{c}$ is pair-wise stable when

$$
(1-\phi(2))^{N-2}\left[x(1)(1-\phi(1))^{2}-x(2)(1-\phi(2))\right] \geq \pi(2)
$$


Proposition 10 When $\underline{n}^{*}=N$, the empty network is the unique pair-wise stable network.

When $\underline{n}^{*}=N, J_{j}^{i}(N-1)<0$, therefore the only pair-wise stable network is the empty one.

\subsection{The set of pair-wise strongly stable networks}

The concept of strong stability allows to predict which kind of networks are more likely to survive to changes in agreements by any coalition of individuals.

Proposition 11 The complete network $g^{c}$ is pair-wise strong stable if $\phi(1)$ is suffciently small.

That is, the expected benefits of maintaining $N-1$ agreements are higher than the benefits of destroying $N-1$ links when the probability of inspection is sufficiently small. Accordingly, in such a case, the complete network is stable against any changes in links by any coalition of firms.

Claim 3 The empty network $g^{e}$ is the unique pair-wise strong stable when $\underline{n}^{*}=N$.

As before, the large components are more unstable than smaller ones under certain conditions.

Proposition 12 The larger components have more incentives to destroy all its agreements at once when the probability of being detected increases more than the fine imposed to a guilty firm as the number of agreements increases.

The benefits of reneging all agreements is higher in lager components since, in such a cases, these markets are more profitable, i.e., they have less number of competitors. Additionally, firms in larger components have less incentive to maintain all their agreements because the probability of being detected increases more than the expected fine as the number of agreements increase. 


\subsection{Examples}

The following examples illustrate the changes that an endogenous antitrust policy imposes in the set of pair-wise stable networks. ${ }^{20}$

Example 3 Pair-wise stable (ps) networks. Cournot competition with exponential inverse demand function $P(Q)=e^{-Q}$

Assume that $N=5$. For an exponential inverse demand function, the profit will be $\pi(n)=e^{-n}$. In the present context, the probability with which a firm will be inspected 21 depends on the number of agreements that it has signed, i.e. it depends on the number of active firms in that market.

The following table depicts different examples of antitrust policy in the current context. The table show the relationship between the number of active firms in a market with the probability with which a firm will be inspected. All these functions satisfy the properties established for $\phi(n)$.

\section{Table 4}

Antitrust Policies

\begin{tabular}{rrrr}
\hline$n_{i}$ & $\phi_{1}\left(n_{i}\right)$ & $\phi_{2}\left(n_{i}\right)$ & $\phi_{3}\left(n_{i}\right)$ \\
\hline 1 & 0.600 & 0.600 & 1.000 \\
2 & 0.125 & 0.250 & 0.590 \\
3 & 0.012 & 0.064 & 0.333 \\
4 & 0.004 & 0.041 & 0.062 \\
5 & 0.002 & 0.022 & 0.040 \\
\hline
\end{tabular}

Thus, for example, when $\phi_{i}\left(n_{i}\right)=\phi_{2}\left(n_{i}\right)$ and $n_{i}=3$ the probability of inspect a given firm $i$ is $\phi_{2}(3)=0.064$.

The alternative policies in the table are ordered from lowest to highest sensitivity to the number of active firms in a market. For them, I compute the function $J_{j}^{i}$ that defines $\underline{n}^{*}$ and $\bar{m}^{*}$. Then, I obtain the set of pair-wise stable networks.

\footnotetext{
${ }^{20}$ See Appendix for all calculation details.

${ }^{21}$ When the antitrust authority is exogenous, the probability of inspection is constant.
} 
Table 5

\begin{tabular}{|c|c|c|c|}
\hline$\phi_{i}\left(n_{i}\right)$ & $\underline{n}^{*}$ & $\bar{m}^{*}$ & Set of pair-wise stable networks \\
\hline$\phi_{1}\left(n_{i}\right)$ & 2 & 3 & | \\
\hline$\phi_{2}\left(n_{i}\right)$ & 3 & 2 & $>\quad{ }_{i} \wedge$ \\
\hline$\phi_{3}\left(n_{i}\right)$ & 4 & 1 & - \\
\hline
\end{tabular}

The fourth column in the table illustrates the set of pair-wise stable networks. For example, when $\phi_{i}\left(n_{i}\right)=\phi_{2}\left(n_{i}\right)$, the set of pair-wise stable networks is composed by three networks. One of them is composed by one component of four firms and one isolated player. The second element in the set is a network formed by only one component. Finally, the last element in the set is a network that is decomposed by two complete components, one of them formed by three firms and the other one by two firms. In the first two network configurations, the components are incomplete. They are pair-wise stable because no firm has incentives to sign one more agreement, seeing that $m_{i}=\bar{m}^{*}$ for all $i$ different from the isolated firm.

From the table, it follows that as the policy becomes more sensitivity to the number of active firms in a market, the maximal number of agreements that a firm may have decreases. This restricts network configurations that may appear by allowing that more competitive networks may arise as pair-wise stable. This is a positive impact of the antitrust authorities.

Now, I use the condition (7) to obtain the set of pair-wise strong stable networks.

Example 4 Pair-wise strongly stable (pss) networks. Cournot competition for exponential inverse demand function: $P(Q)=e^{-Q}$

Following the last example, I assume that $N=5$. I check whether the condition (7) holds for all network configurations in Table 5 for the different antitrust policies. According to this, the set of strong stable networks is as follow: 
Table 6

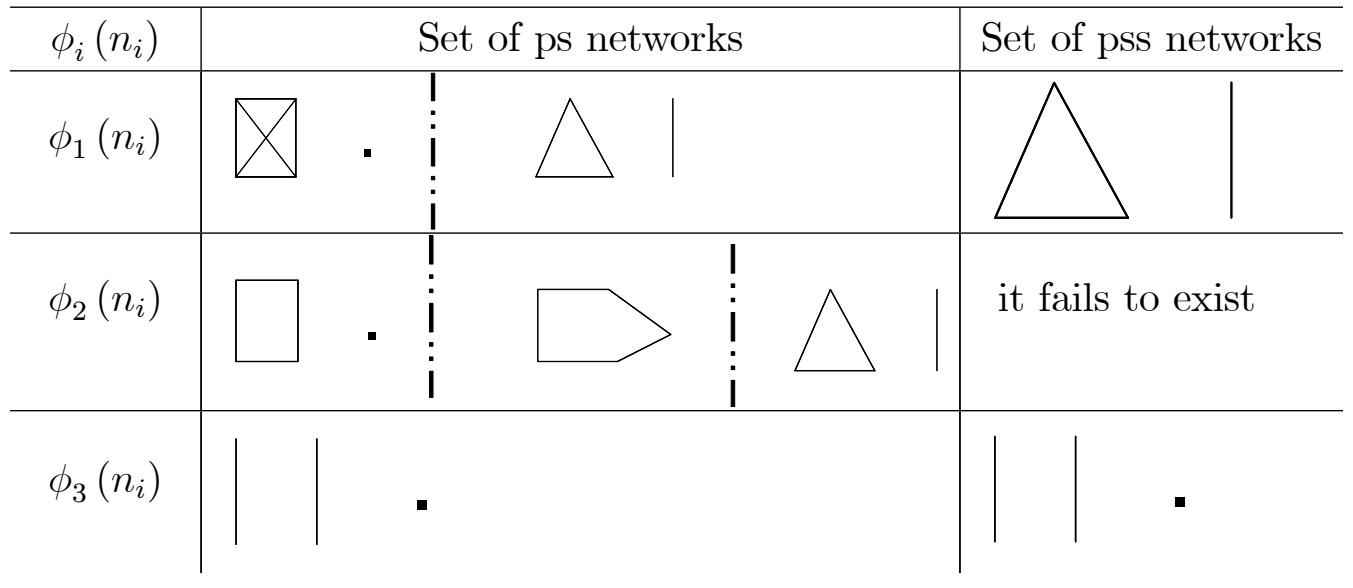

Similarly to the exogenous context, when I apply the strong condition, the set of pair-wise strong stable networks is reduced and sometimes it fails to exist. The strong stable criterion provides a more accurate prediction about what kind of network configurations may sustain in the time. Moreover, when $\phi_{i}\left(n_{i}\right)=\phi_{1}\left(n_{i}\right)$, the network $\{4,1\}$ does not pass the strong stable condition and, in this case, it is not strong stable. This is in line with what Proposition 12 establishes, i.e., larger components are more sensitive to the antitrust policy.

\section{The AA and its effects on competition}

From the previous analysis, we conclude that, when the AA set a fixed probability of inspection, for $\alpha$ sufficiently small the complete network appears as pair-wise stable. As $\alpha$ increases the smaller alliances are first in being destroyed by the antitrust policy. In turn, the set of isolated firms expands.

Moreover, as $\alpha$ becomes larger, $m\left(g_{h}^{*}\right)$ also increases. From Proposition 7, however, we know that large alliances are harder to sustain.

Therefore, as $\alpha$ increases, the empty network, $g^{e}$, tends to emerge as the only pairwise strongly stable network. Let us recall that in an empty network, all firms are active in all markets. Then, we infer that the antitrust policy is a pro-competitive one.

On the other hand when the AA responds to the suspicion of the consumer, components are not necessary complete in pair-wise stable networks. This is an important result for the effect of the AA on competitions since this implies that more competitive structure may arise with respect to the first case. Moreover, the empty network arises 
as unique pair-wise stable when the policy is sufficiently sensitivity to the claims of consumers.

As it is well known, in Cournot oligopolies with homogeneous goods, the social surplus $(V)$ is increasing in the number of active firms on the market.

When $\alpha(\cdot)$ is sufficiently high, the $g^{e}$ is the only network that prevails over time. Therefore, in such a case, $V$ would be the maximum.

Although this probability of inspection may be the "advice" to give to the AA in the case of it fix that probability, it may not be the optimal antitrust policy, because the necessary costs to attain that enforcement level may outweigh its positive impact on the social surplus. That is, in order to know whether the AA has a net positive effect on social welfare, we must also consider the cost of enforcement.

Thus, the net social welfare, $W$, depends on the network structure $g$ (which depends, at last, on the particular level of $\alpha(\cdot))$, as well as, on the cost of initiating a marketsharing agreement suit against a firm, $C(\alpha(\cdot))$.

Hence, if the AA were concerned about the optimal antitrust policy, then it would have to choose $\alpha$ such that maximizes

$$
W(g(\alpha), C)=V(g(\alpha(\cdot)))-C(\alpha(\cdot))
$$

Unfortunately, the optimal antitrust policy is difficult to evaluate in our context because of to the multiplicity on network configurations for each level of antitrust enforcement. In our network context, $g(\alpha(\cdot))$ is not unique for each $\alpha(\cdot)$. Moreover, a particular network $g$ can emerge as pair-wise stable for different levels of $\alpha(\cdot)$.

\section{Concluding Remarks}

Under two different settings of antitrust policy, we have studied the stable collusive network that arises when firms sign market-sharing agreements among themselves in a symmetric oligopolistic framework.

Naturally, the presence of an AA weakens firm's incentives to participate in a collusive agreement because it reduces the net expected benefit from signing them. In the current network framework, the channels through which antitrust policy impacts on competition has its peculiarities. Firms, considering whether to sign an agreement, take into account the probability of being discovered rather than the probability of being inspected, and the first probability positively depends on the number of agreements 
that each firm has signed.

We analyze a case where the probability of inspection is constant and the penalty that the AA imposes is equal to the total profits of a guilty firm. In such a case, that penalty depends on the network configuration as a whole. On the other hand, when the AA is endogenous, both the probability of inspection and the penalty depend on the network configuration.

When the probability of inspection is constant and the penalty is equal to the total profit of a guilty firm, we have shown that, the pair-wise stable network can be decomposed into a set of isolated firms and complete components of different sizes. When the AA exists, however, we cannot define a unique lower bound on the size of complete components because it now depends on each network configuration and on the probability that a firm being inspected. In turn, this implies that, although the lower bound on the size of complete components may be greater than when the AA does not exist, the set of isolated firms enlarges and, finally, more structures that are competitive can be sustained through bilateral agreements.

On the other hand, when the antitrust policy is an endogenous one, the set of pairwise stable network can be partitioned into a set of isolated player and components that are not necessarily fully interconnected. Given $N$, we can define a lower bound on the size of components. This bound is also related with the number of isolated firms.

The lower bound on the size of components has an important impacts on defining competition on the market. As the minimal number of firms active in a market that are necessary for make an agreement profitable increases, it is possible to expect more competitive structure. The comparison of this lower bound in both case, exogenous and endogenous antitrust policy, is not straightforward as the lower bound in the first case depends on the network configuration.

We have also shown that antitrust laws, in both cases, have a pro-competitive effect, as they give firms in large alliances more incentives to cut their agreements at once. Therefore, the empty network might arise as the only strongly stable network.

An important policy implication of the present formulation is that the organization of the illegal behavior matters. That is, the analysis of the optimal deterrence of marketsharing agreements has to take into account the organizational structure of collusive firms. Furthermore, without considering the effects of the organizational structure, empirical studies may overestimate the contribution of efforts devoted to investigate 
and prosecute collusive agreements. ${ }^{22}$

In this article, we consider a relatively simple setting for analyzing the effect of the antitrust policy on the structure of criminal behavior. A particular extension form here is how the internal structure of these conspiracies may affect their observable behavior, which, in turn, may throw some light on the optimal antitrust policy.

\section{Appendix}

Proof Proposition 1 Roldán (2008) provides necessary conditions on stability. Now, let us consider the sufficient part. Consider a network $g$ that can be decomposed into a set of isolated firms and distinct complete components, $g_{1}, \ldots, g_{L}$ of different sizes $m\left(g_{l}\right) \neq m\left(g_{l^{\prime}}\right), \forall l, l^{\prime}$. Isolated players have no incentive to create a link with another isolated one. As long as a firm $i$, that belongs to the smallest component, does not have incentives to cut a link with a firm inside its component, then, by Lemma 3, no firm inside a component has incentives to cut a link. Additionally, given that $m\left(g_{l}\right) \neq m\left(g_{l^{\prime}}\right), \forall l, l^{\prime}$, there do not exist two firms belonging to different components that have an incentive to form an agreement between themselves.

Proof Proposition $2 \Rightarrow$ Consider a pair-wise strong Nash equilibrium $s^{*}$. Given that any strongly pair-wise stable network is pair-wise stable, $g\left(s^{*}\right)$ can be decomposed into a set of isolated firms and complete components where no isolated firm wants to form a link with another isolated one and (??) holds. But assume, by contradiction, that some component $g_{l}$ does not satisfy the condition $(1-\alpha)^{m} \pi(N-m+1) \geq \pi(N)+$ $(m-1) \pi(N-m+2)+\sum \pi\left(n_{k}\right)\left(1-(1-\alpha)^{m}\right) \forall m=m\left(g_{l}\right)$. Then $s^{*}$ is not a Nash equilibrium because any firm $i$ in $g_{l}$ has a profitable deviation by choosing $s_{i}^{\prime}=\emptyset$.

$\Longleftarrow$ Assume network $g$ can be decomposed into a set of isolated firms and complete components of different sizes, where inequality (??) holds. Also assume that $(1-\alpha)^{m} \pi(N-m+1) \geq \pi(N)+(m-1) \pi(N-m+2)+\sum \pi\left(n_{k}\right)\left(1-(1-\alpha)^{m}\right)$ holds for all $m=m\left(g_{l}\right)$. We will show that the following strategies form a pair-wise strong Nash equilibrium. For firm $i \in g_{l}$ it announces $s_{i}^{*}=\left\{j \mid j \in g_{l}, j \neq i\right\}$, however, if $i$ is isolated, it announces $s_{i}^{*}=\emptyset$. Hence,

a) No isolated firm $i$ has an incentive to create a link with another firm $j$, as $i \notin s_{j}^{*}$.

\footnotetext{
${ }^{22}$ Some empirical papers that estimate the deterrent effect of the policy are, among others, Buccirossi and Spagnolo,2005; Connor, 2006; Zimmerman and Connor, 2005.
} 
b) $\operatorname{As}(1-\alpha)^{m} \pi(N-m+1) \geq \pi(N)+(m-1) \pi(N-m+2)+\sum \pi\left(n_{k}\right)\left(1-(1-\alpha)^{m}\right)$ holds for all $m=m\left(g_{l}\right)$, the firm has no incentive to destroy all its $m$ links. We must consider, however, the firm's incentives to cut a subset of them. Let us assume it has an incentive to delete a strict subset of its links, hence, it chooses to delete $h$ links because

$$
(1-\alpha)^{h} \pi(N-m+1)<\pi(N-m+1+h)+h \pi(N-m+2)+\sum \pi\left(n_{k}\right)\left(1-(1-\alpha)^{h}\right)
$$

Given that $h \geq 1$, then

$$
\pi(N-m+1+h)+h \pi(N-m+2) \leq(h+1) \pi(N-m+2)
$$

Because of we are considering a strict subset of links, then $h<m-1$ and $h+1<m-1$, hence

$$
(h+1) \pi(N-m+2)<(m-1) \pi(N-m+2)
$$

Therefore

$$
(1-\alpha)^{m} \pi(N-m+1)<(1-\alpha)^{h} \pi(N-m+1)<(m-1) \pi(N-m+2)
$$

that contradicts our hypothesis.

c) No firm $i \in g_{l}$ has an incentive to create a link with firm $j \in g_{l^{\prime}}$ as $i \notin s_{j}^{*}$. Moreover, as $m\left(g_{l}\right) \neq m\left(g_{l^{\prime}}\right)$ for all $l \neq l^{\prime}$, no pair of firms $i \in g_{l}$ and $j \in g_{l^{\prime}}$ has an incentive to create a new link between them.

d) $\operatorname{As}(1-\alpha)^{m} \pi(N-m+1) \geq \pi(N)+(m-1) \pi(N-m+2)+\sum \pi\left(n_{k}\right)\left(1-(1-\alpha)^{m}\right)$ holds for all $m=m\left(g_{l}\right)$, when $m>3$, no pair of firms have incentives to delete all their links nor a subsets of their agreements and to form a link between them. Let us assume, by contradiction, a pair of firms, $i \in m$ and $j \in m^{\prime}$, has incentive to destroy all their $m$ and $m^{\prime}$ links each and form a link between them. For firm $i$, this is

$$
\begin{aligned}
& (1-\alpha)^{m-2} \pi(N-m+1) \\
< & \pi(N-1)+(m-1) \pi(N-m+2)+\left(m^{\prime}-1\right) \pi\left(N-m^{\prime}+2\right)+ \\
+ & \sum_{k \neq j \neq i, g_{i k=0},} \pi\left(n_{k}\right)-(1-\alpha)^{m-2}\left[\sum_{k \neq j \neq i, g_{i k=0},} \pi\left(n_{k}\right)+m^{\prime} \pi\left(N-m^{\prime}+1\right)\right]
\end{aligned}
$$

Given that, the LHS(14)>LHS(6) and by straightforward computations we can show that RHS(6)>RHS(14), when condition(6) holds then LHS(14)>RHS(14), which con- 
tradicts (14)

Proof Proposition $3 \quad(\Longrightarrow)$ If $g^{c}$ is pair-wise stable then

$$
(1-\alpha) \pi(1) \geq 2 \pi(2)
$$

By rewriting the last condition, we get $\alpha \leq \alpha^{c}=1-\frac{2 \pi(2)}{\pi(1)}$.

$(\Longleftarrow)$ If $\alpha \leq \alpha^{c}=1-\frac{2 \pi(2)}{\pi(1)}$, then $(1-\alpha) \pi(1) \geq 2 \pi(2)$. Therefore, $g^{c}$ will be pair-wise stable.

Proof Proposition 4 Assume that $N \geq 3$.

$(\Longrightarrow)$ If $g^{e}$ is pair-wise stable then,

$$
(1-\alpha)^{2}[\pi(N-1)+(N-2) \pi(N)]<\pi(N)+\pi(N)+(N-2) \pi(N)
$$

and, by straightforward calculation,

$$
\alpha>1-\left[\frac{N \pi(N)}{[\pi(N-1)+(N-2) \pi(N)]}\right]^{\frac{1}{2}}=\alpha_{e}(N)
$$

$(\Longleftarrow)$ If $\alpha>\alpha_{e}(N)$, then (10) holds. Therefore, $g^{e}$ is pair-wise stable.

Proof Proposition 5 For simplicity, let us assume two complete components $g_{1}$ and $g_{2}$. For each firm $i \in g_{1}, n_{1}$ is the number of active firms in its market, and for each firm $j \in g_{2}, n_{2}$ is the number of active firms in its market.

Let us define $\alpha^{*}\left(n_{i}\right):=\frac{\pi\left(n_{i}-1\right)-2 \pi\left(n_{i}\right)}{\pi\left(n_{i}-1\right)+\sum_{k \neq j, g i=0} \pi\left(n_{k}\right)}$.

We are interested to know whether $\alpha^{*}\left(n_{1}\right) \lessgtr \alpha^{*}\left(n_{2}\right)$. That is,

$$
\frac{\pi\left(n_{1}-1\right)-2 \pi\left(n_{1}\right)}{\pi\left(n_{1}-1\right)+\left(N-n_{2}+1\right) \pi\left(n_{2}\right)} \lessgtr \frac{\pi\left(n_{2}-1\right)-2 \pi\left(n_{2}\right)}{\pi\left(n_{2}-1\right)+\left(N-n_{1}+1\right) \pi\left(n_{1}\right)}
$$

By solving the last expression, we get

$$
\begin{aligned}
& \left(N-n_{1}+1\right) \pi\left(n_{1}\right) \pi\left(n_{1}-1\right)-2 \pi\left(n_{1}\right) \pi\left(n_{2}-1\right)-2\left(N-n_{1}+1\right)\left[\pi\left(n_{1}\right)\right]^{2} \lessgtr \\
& \left(N-n_{2}+1\right) \pi\left(n_{2}\right) \pi\left(n_{2}-1\right)-2 \pi\left(n_{2}\right) \pi\left(n_{1}-1\right)-2\left(N-n_{2}+1\right)\left[\pi\left(n_{2}\right)\right]^{2}
\end{aligned}
$$


In order to decide the sense of the inequality, we rearrange the above expression into the following two parts:

$$
\begin{gathered}
\left(N-n_{1}+1\right) \pi\left(n_{1}\right)\left[\pi\left(n_{1}-1\right)-2 \pi\left(n_{1}\right)\right] \lessgtr\left(N-n_{2}+1\right) \pi\left(n_{2}\right)\left[\pi\left(n_{2}-1\right)-2 \pi\left(n_{2}\right)\right] \\
\pi\left(n_{1}\right) \pi\left(n_{2}-1\right) \lessgtr \pi\left(n_{2}\right) \pi\left(n_{1}-1\right)
\end{gathered}
$$

If $n_{1}>n_{2}$, then (i) $\left(N-n_{1}+1\right)<\left(N-n_{2}+1\right)$; (ii) by Property $1, \pi\left(n_{1}\right)<\pi\left(n_{2}\right)$; (iii) by Property $2,\left[\pi\left(n_{1}-1\right)-2 \pi\left(n_{1}\right)\right]<\left[\pi\left(n_{2}-1\right)-2 \pi\left(n_{2}\right)\right]$.

Therefore,

$$
\left(N-n_{1}+1\right) \pi\left(n_{1}\right)\left[\pi\left(n_{1}-1\right)-2 \pi\left(n_{1}\right)\right]<\left(N-n_{2}+1\right) \pi\left(n_{2}\right)\left[\pi\left(n_{2}-1\right)-2 \pi\left(n_{2}\right)\right]
$$

Additionally, if $n_{1}>n_{2}$, then, by Property $3, \frac{\pi\left(n_{2}-1\right)}{\pi\left(n_{2}\right)}>\frac{\pi\left(n_{1}-1\right)}{\pi\left(n_{1}\right)}$

Hence,

$$
\pi\left(n_{1}\right) \pi\left(n_{2}-1\right)>\pi\left(n_{2}\right) \pi\left(n_{1}-1\right)
$$

Therefore, if, $n_{1}>n_{2}$, by (11) and (12), then

$$
\alpha^{*}\left(n_{1}\right)<\alpha^{*}\left(n_{2}\right)
$$

Proof Proposition 6 By Claim 1, we know that, at $\alpha=\alpha^{c}, g^{e}$ and $g^{c}$ are pair-wise stable.

Now, we must check, for $\alpha=\alpha^{c}$, whether a firm $i$ has incentive to form an additional agreement when $n \neq 1$ and $n \neq N$.

Therefore, we must verify whether $J_{j}^{i} \lessgtr 0$, that is,

$$
\pi(n-1)-2 \pi(n) \lessgtr \alpha\left(\pi(n-1)+\sum_{k \neq j, g_{k i}=0} \pi\left(n_{k}\right)\right)
$$

At $\alpha=\alpha^{c}$, the above expression is

$$
\pi(n-1)-2 \pi(n) \lessgtr\left[1-\frac{2 \pi(2)}{\pi(1)}\right]\left(\pi(n-1)+\sum_{k \neq j, g_{k i}=0} \pi\left(n_{k}\right)\right)
$$


After some calculations, we obtain

$$
2[\pi(n-1) \pi(2)-\pi(n) \pi(1)] \lessgtr \sum_{k \neq j, g_{k i}=0} \pi\left(n_{k}\right)[\pi(1)-2 \pi(2)]
$$

By Property $2, \pi(1)-2 \pi(2)>0$, and by Property $3,[\pi(n-1) \pi(2)-\pi(n) \pi(1)]<$ 0 . Therefore, at $\alpha=\alpha^{c}$,

$$
J_{j}^{i}<0
$$

Proof Proposition 7 The partial derivative of (6) respect to $\alpha$ is:

$$
-(m+1)\left[\pi(N-m+1)+\sum \pi\left(n_{k}\right)\right](1-\alpha)^{m}
$$

That is, as $\alpha$ increases, the incentive to maintain links decreases.

Now, we must check whether (13) is larger for firms in large component. Without loss of generality, assume that there are two components whose sizes are $m_{1}+1$ and $m_{2}+1$ respectively, such that $m_{1}>m_{2}$. After some computations, we can verify that, for a sufficiently high $m$, the following holds:

$$
\begin{aligned}
& -\left(m_{1}+1\right)\left[\pi\left(N-m_{1}+1\right)+m_{2} \pi\left(N-m_{2}+1\right)\right](1-\alpha)^{m_{1}}< \\
& -\left(m_{2}+1\right)\left[\pi\left(N-m_{2}+1\right)+m_{1} \pi\left(N-m_{1}+1\right)\right](1-\alpha)^{m_{2}}
\end{aligned}
$$

Proof Proposition 8 Assume a network $g$ is pair-wise stable. For all $m>\bar{m}^{*}$ and for all $m<\underline{\mathrm{m}}^{*} J_{j}^{i}<0$. Therefore, in a pair-wise stable network, no firm has more than $\bar{m}^{*}$ agreements and no less than $\underline{m}^{*}$.

a) Firstly, given a component of size $m\left(g_{l}\right)$, the number $m\left(g_{l}\right)-1$ represents the maximal number of agreement that every firm in $g_{l}$ may have. Recall that $\bar{m}^{*}$ is the maximal number of agreement such that $J_{j}^{i} \geq 0$. Since components are symmetric, every firm in $g_{l}$ has the same number of agreements. That is, for all pair of firms $i$ and $j$ that belong to $g_{l}$, then $m_{i}=m_{j}=m$.

Assume that $i$ and $j$ belong to $g_{l}$ but $g_{i j}=0$, if $m<m\left(g_{l}\right)-1 \leq \bar{m}^{*}$, firms $i$ and $j$ will have incentives to form an agreement between them as $m<\bar{m}^{*}$. But it is a contradiction with the assumption of pair-wise stability of network $g$. Then, if $m\left(g_{l}\right)-1 \leq \bar{m}^{*}$ all components must be complete and its member will have at most $\bar{m}^{*}$ agreements. 
Second, let us assume that there exist two largest components such that their sizes are equal to $\bar{m}^{*}+1$. As we have shown, these components must be complete and every firm inside them has $\bar{m}^{*}$ agreements. No firm inside these components has incentives to sever a link with a firm in the component as each firm in them has $\bar{m}^{*}$ agreements. Let us consider now a link between two firms belonging to each component. These firms have no incentives to sign one more agreements, as long as each one has $\bar{m}^{*}$ agreements, and this number is the largest number of links such that $J_{j}^{i} \geq 0$.

Finally, let us consider a firm $i \in g_{1}$ and $j \in g_{2}$ such that $\bar{m}^{*}>m\left(g_{1}\right)>m\left(g_{2}\right)$. The firm $j$, that belongs to the smaller component, refuses to sign an agreement with $i$, since $n_{i}<n_{j}$ and then, $\pi\left(n_{j}-1\right)-\pi\left(n_{i}\right)<0$.

As $N-\bar{n}>1$, the isolated players have no incentives to form any agreements.

b) Assume $m\left(g_{l}^{\prime}\right)=\max _{l=1,2, \ldots, p}\left\{m\left(g_{l}\right)\right\}>\bar{m}^{*}+1$. Therefore, $m\left(g_{l}^{\prime}\right)-1>\bar{m}^{*}$. Since $\bar{m}^{*}$ is the maximal number of links such that $J_{j}^{i} \geq 0$, every firm in $g_{l}^{\prime}$ has $\bar{m}^{*}$ agreements and then $g_{l}^{\prime}$ will not be fully interconnected. If each firm in $g_{l}^{\prime}$ has lesser agreements than $\bar{m}^{*}$, it will have incentives to form one more link. If a firm inside this component has more agreements than $\bar{m}^{*}$ and/or the component is fully interconnected, every firm inside $g_{l}^{\prime}$ will have incentives to sever a link, as long as $m\left(g_{l}^{\prime}\right)-1>\bar{m}^{*}$, and thus $g$ would not be pair-wise stable.

Let us assume now another component $g_{l}^{\prime \prime}$ such that $\bar{m}^{*}+1<m\left(g_{l}^{\prime \prime}\right) \leq m\left(g_{l}^{\prime}\right)=\max _{l=1,2, \ldots, p}\left\{m\left(g_{l}\right)\right\}$. As before, $g_{l}^{\prime \prime}$ will not be fully interconnected and its members will have $\bar{m}^{*}$ links. No firm inside $g_{l}^{\prime \prime}$ has incentives to cut a link as it has $\bar{m}^{*}$ agreements. Moreover, no firm in $g_{l}^{\prime \prime}$ has incentives to sign another agreements since it has $\bar{m}^{*}$ links.

Finally, let us consider that $g_{l}^{\prime \prime}$ is such that $m\left(g_{l}^{\prime \prime}\right) \leq \bar{m}^{*}+1$. Then, it follows the proof in a).

As $N-\bar{n}>1$, the isolated players have no incentives to form any agreements.

Proof Proposition $9 \Rightarrow$ Consider a pair-wise strong Nash equilibrium $s^{*}$. Given that any strongly pair-wise stable network is pair-wise stable, $g\left(s^{*}\right)$ can be decomposed as Proposition XXXX and (7) holds. But assume, by contradiction, that some component $g_{l}$ does not satisfy that condition. Then $s^{*}$ is not a Nash equilibrium because any firm $i$ in $g_{l}$ has a profitable deviation by choosing $s_{i}^{\prime}=\emptyset$.

$\Longleftarrow$ Assume network $g$ can be decomposed as Proposition XXX, where inequality (7) holds. We will show that the following strategies form a pair-wise strong Nash equilibrium. For firm $i \in g_{l}$ it announces $s_{i}^{*}=\left\{j \mid j \in g_{l}, j \neq i\right\}$, however, if $i$ is isolated, it announces $s_{i}^{*}=\emptyset$. Hence, 
a) No isolated firm $i$ has an incentive to create a link with another firm $j$, as $i \notin s_{j}^{*}$.

b) As $\pi(n)-x(n) \varphi(n, n) \geq \pi(N)+m \pi(N-m+1)$ holds for all $m=m\left(g_{l}\right)$, the firm has no incentive to destroy all its $m$ links. We must consider, however, the firm's incentives to cut a subset of them. Let us assume it has an incentive to delete a strict subset of its links, hence, it chooses to delete $h$ links because

$$
\pi(n)-x(n) \varphi(n, n)<\pi(N-m+h+1)+h \pi(n+1)
$$

Given that $h \geq 1$, then

$$
\pi(N-m+h+1)+h \pi(n+1) \leq(h+1) \pi(N-m+1)
$$

Because of we are considering a strict subset of links, then $h<m-1$ and $h+1<m-1$, hence

$$
(h+1) \pi(N-m+1)<m \pi(N-m+1)
$$

Therefore

$$
\pi(n)-x(n) \varphi(n, n)<m \pi(N-m+1)
$$

that contradicts our hypothesis.

c) No firm $i \in g_{l}$ has an incentive to create a link with firm $j \in g_{l^{\prime}}$ as $i \notin s_{j}^{*}$.

d) $\pi(n)-x(n) \varphi(n, n) \geq \pi(N)+m \pi(N-m+1)$ holds for all $m=m\left(g_{l}\right)$, when $m>3$, no pair of firms have incentives to delete all their links nor a subsets of their agreements and to form a link between them. Let us assume, by contradiction, a pair of firms, $i \in m$ and $j \in m^{\prime}$, has incentive to destroy all their $m$ and $m^{\prime}$ links each and form a link between them. For firm $i$, this is

$$
\begin{aligned}
& (1-\alpha)^{m-2} \pi(N-m+1) \\
< & \pi(N-1)+(m-1) \pi(N-m+2)+\left(m^{\prime}-1\right) \pi\left(N-m^{\prime}+2\right)+ \\
+ & \sum_{k \neq j \neq i, g_{i k=0},} \pi\left(n_{k}\right)-(1-\alpha)^{m-2}\left[\sum_{k \neq j \neq i, g_{i k=0},} \pi\left(n_{k}\right)+m^{\prime} \pi\left(N-m^{\prime}+1\right)\right]
\end{aligned}
$$

Given that, the LHS(14)>LHS(6) and by straightforward computations we can show that RHS(6)>RHS(14), when condition(6) holds then LHS(14)>RHS(14), which contradicts (14). 
Proof Proposition 10 Assume $g_{i j}=1$. Then, $n_{i}=n_{j}=n$. Therefore, $J_{j}^{i}$ can be written as

$\pi(n)-2 \pi(n+1)-\left[\pi(n)-\pi(n+1)-\prod_{j \text { st } g_{i j}=1}(1-\phi(n+1))\left[x(n)(1-\phi(n))^{2}-x(n+1)(1-\phi(n+\right.\right.$

We must prove now that when $n=1$, this expression is negative. That is, we must prove that:

$$
-\pi(2)+(1-\phi(2))^{N-2}\left[(\pi(1)-\pi(N))(1-\phi(1))^{2}-(\pi(2)-\pi(N))(1-\phi(2))\right]<0
$$

For that, let us verify that the sign of bracket expression is also negative. First of all, let us observe that $\left[(1-\phi(2))-(1-\phi(1))^{2}\right]>0$. Therefore,

$\pi(N)\left[(1-\phi(2))-(1-\phi(1))^{2}\right]<\pi(2)\left[(1-\phi(2))-(1-\phi(1))^{2}\right]<\pi(2)(1-\phi(2))-\pi(1)(1-\phi(1))$

Consequently, $\underline{n}^{*}$ must be greater than 1 and the complete network will never be stable.

When the industry is "sufficiently" large, the empty network emerge as a pair-wise stable network.

Proof Proposition $11 N-\bar{n}^{*}=\underline{m}^{*}$. We interpret $\underline{m}^{*}$ as the minimal number of agreement that a firm has to have in order to form an additional one Therefore, when $N-\bar{n}^{*}=1$ any two firm has incentive to form an additional agreement. However, if $N-\bar{n}^{*}>1$ any two firms need to have more than one agreement in order to make profitable to form an additional link.

Proof Proposition 12 Assume $n_{1}<n_{2}$. As the number of agreements increases, a firm balances the pros and cons whether to maintain or cut its agreements. Namely, if a firm maintains its agreements, its benefits are $x(n)(1-\phi(n))^{n+1}$. If a firm destroys its agreements, it gains $(N-n) \pi(n+1)$.

Consequently, if $\frac{x\left(n_{1}\right)}{x\left(n_{2}\right)}-1<\frac{\left(1-\phi\left(n_{2}\right)\right)^{n_{2}+1}}{\left(1-\phi\left(n_{1}\right)\right)^{n_{1}+1}}-1$, a firm in large component has less incentives to maintain all its agreements than a firm that belongs to a smaller one, since $x\left(n_{1}\right)\left(1-\phi\left(n_{1}\right)\right)^{n_{1}+1}<x\left(n_{2}\right)\left(1-\phi\left(n_{2}\right)\right)^{n_{2}+1}$.

On the other hand, a firm in a large component has more incentives to cut all its 
agreements at once than a firm that belong to a smaller one, inasmuch as $\left(N-n_{1}\right) \pi\left(n_{1}+1\right)>$ $\left(N-n_{2}\right) \pi\left(n_{2}+1\right)$ given convexity assumption.

\section{References}

[1] Aumann, R. and Myerson, R. 1988. "Endogenous formation links between players and coalitions: an application of the Shapley value." In Roth, A. The Shapley Value. Cambridge University Press, Cambridge, United Kingdom, 1988.

[2] Ballester, C., Calvó-Armengol, A. and Zenou, Y. "Who's who in networks. Wanted: the key player." Econometrica, Vol. 74 (2006), pp. 1403-1417.

[3] Becker, G. "Crime and Punishment: An economic approach." Journal of Political Economy, Vol. 76 (1968), pp. 169-217.

[4] Belleflamme, P. and Bloch, F. "Market-sharing agreements and collusive networks." International Economic Review, Vol. 45 (2004), pp. 387-411.

[5] Besanko, D. and Spulber, D. "Antitrust enforcement under asymmetric information." The Economic Journal, Vol. 99 (1989), pp. 408-425.

[6] and "Are Treble Damages Neutral? Sequential Equilibrium and Private Antitrust Enforcement." American Economic Review, Vol. 80 (1990), pp. 870-887.

[7] Block, M. et al "The deterrent effect of antitrust enforcement." Journal of Political Economy, Vol. 89 (1981), pp. 429-445.

[8] Calvó-Armengol, A. and Zenou, Y., "Social networks and crime decisions: the role of social structure in facilitating delinquent behavior." International Economic Review, Vol. 45 (2004), pp. 939-958.

[9] Chen, Z. and Rey,P., "On the design of Leniency Programs", Working Paper, No. 452, IDEI, University of Toulouse, 2007.

[10] D'Aspremont, C et al "On the stability of Collusive Price Leadership". Canadian Journal of Economics, Vol. 16 (1983), pp. 17-25.

[11] Deneckere, R. and Whinston, M. "Multimarket contact and collusive behavior." Rand Journal of Economics, Vol. 21 (1990), pp. 1-26. 
[12] Dutta, B. and Mutuswami, S. "Stable Networks." Journal of Economic Theory, Vol. 76 (1997), pp. 322-344.

[13] Goyal, S., "Sustainable Communications Networks." Discussion Paper TI 93-250, Tinbergen Institute, 1983.

[14] — and Joshi, S. "Networks of Collaboration in Oligopoly." Games and Economic Behavior, Vol. 43 (2003), pp. 57-85.

[15] — , and Moraga, J. "R\&D Networks." Rand Journal of Economics, Vol. 32 (2001), pp. 686-707.

[16] Harrington, Jr.,J.E. "Some implications of antitrust laws of cartel pricing." Economics Letters, Vol. 79 (2003), pp. 377-383.

[17] Harrington, Jr.,J.E. "Cartel Pricing Dynamics in the Presence of an Antitrust Authority." Rand Journal of Economics, Vol. 35 (2004), pp. 651-673

[18] Harrington, Jr.,J.E. "Optimal Cartel Pricing in the. Presence of an Antitrust Authority." International Economic Review, Vol. 46 (2005), pp. 145-169

[19] Jackson, M. and A. van den Nouweland "Strongly stable networks." Games and Economic Behavior, Vol. 51 (2005), pp. 420-444.

[20] and Wolinsky, A. "A strategic model of social and economic networks." Journal of Economic Theory, Vol. 71 (1996), pp. 44-74.

[21] LaCasse, C. "Bid Rigging and the Threat of Government Prosecution." Rand Journal of Economics, Vol. 26 (1995), pp. 398-417

[22] Motchenkova et al "Antitrust enforcement under endogenous fines and pricedependent detection probabilities", TILEC Discussion Paper, DP 2010-020.

[23] Motta, M., Competition Policy: Theory and Practice. Cambridge University Press, 2004.

[24] and Polo, M. "Leniency Programs and Cartel Prosecution." International Journal of Industrial Organization, Vol. 21 (2003), pp. 347-379.

[25] Myerson, R.B., Game theory: Analysis of conflict. Cambridge, MA: Harvard University Press, 1991. 
[26] Mitchell Polinsky, A. and Shavell, S. "The economic theory of public enforcement of law." Journal of Economic Literature, Vol. 38 (2000), pp. 45-76.

[27] Polo, M., "The Optimal Prudential Deterrence of Price Fixing Agreements". Working Paper $\mathrm{N}^{\circ}$ 120, IGER, 1997

[28] Rey, P., "Towards a Theory of Competition Policy." Working Paper Nº. 121, IDEI, University of Toulouse, 2002.

[29] Roldán, F. "Collusive Networks in Market Sharing Agreements in the Presence of an Antitrust Authority", Working Paper WP 854, SP-SP Research Center- IESE Business School, April 2010.

[30] Scherer, F. and Ross, D., Industrial Market Structure and Economic Performance, 3rd. Ed. Boston: Houghton-Mifflin, 1990.

[31] Stigler, G. "Monopoly and Oligopoly by Merger." American Economic Review, Vol. 40 (1950), pp. 23-34.

[32] Vives, X., Oligopoly Pricing: Old Ideas and New Tools. The MIT Press Editor, 1999. 